\title{
Colonization of experimentally arranged resource patches - a case study of fungivorous beetles
}

\author{
Anne Sverdrup-Thygeson
}

Sverdrup-Thygeson, A. 2010: Colonization of experimentally arranged resource patches - a case study of fungivorous beetles. - Entomol. Fennica 21: 139-150.

The study focuses on a colonization experiment of beetles, using sporocarps of tinder fungus Fomes fomentarius. Initially, a mapping of all sporocarps of $F$. fomentarius and its inhabitants was made in a 225 ha area of boreal forest in southern Norway (control dataset). $62 \%$ of the sporocarps contained one or more beetle individuals. Experimental sporocarps were then placed out for three years, collected and dissected. $21 \%$ of these were colonized. The comparison between control and experiment showed that species assemblages were rather similar. Successful between-tree colonization and reproduction in experimental sporocarps by the darkling beetle Bolitophagus reticulatus was observed. Cis jacquemartii colonized $14 \%$ of the experimental sporocarps, and there was no effect of distance from known dispersal sources on colonization for this species. This indicates that C. jacquemartii was well able to locate and colonize new substrate within the scale covered in the study.

A. Sverdrup-Thygeson, Norwegian Institute for Nature Research, Gaustadalléen 21,NO-0349 Oslo,Norway; E-mail: anne.sverdrup-thygeson@nina.no

Received 15 February 2010, accepted 18 August 2010

\section{Introduction}

Dispersal is a basic property in ecology and influences the life history of an organism in several ways. In fragmented landscapes of today's world, the dispersal of many species is impeded, as they face isolation between their suitable habitat patches. One such group of species is the saproxylic insects (Speight 1989); the insects dependent on dead and decaying wood or other saproxylic organisms such as wood rotting fungi for their survival. Although modern forest managements, e.g. in Fennoscandia, strives to accommodate the requirements of forest living species through standards of sustainable forest management and principles of forest certification, comparisons indicate that the amount of coarse dead wood in the forest is well below natural conditions (Siitonen 2001). Some saproxylic species have already disappeared; several hundred more are listed on various national Red lists in Northern Europe as in danger of extinction (Balevièius 1992, Lilleleht 1998, Finnish Environment Institute 2000, Gärdenfors 2005, Kålås et al. 2006). The accumulating effect of intensive forest management has also been shown to indicate an extinction debt in saproxylic insects in Finland (Hanski 2000).

The need for better knowledge on how forestry affects saproxylic species is therefore critical. Several studies have been conducted to elucidate the mechanisms of dispersal in saproxylic beetles in Fennoscandia (Sverdrup-Thygeson \& Midtgaard 1998, Ranius \& Hedin 2001, Jonsson 
2003, Gibb et al. 2006b) and other regions (Schiegg 2000, Grove 2002, Starzomski \& Bondrup-Nielsen 2002, Buse et al. 2007), but the interpretation of dispersal patterns is not straightforward. Care must be taken when extrapolating between spatial scales, and when extending the temporal focus. Especially, the effect of rare but successful long distance dispersal events is hard to evaluate, and such events are easily missed in field studies.

One challenge in dispersal studies of insects is to find sound methods. In a review paper Ranius (2006) lists several examples of possible methods, such as capture-recapture methods, telemetry, studies of occurrence patterns, genetic studies, observations of flight in field or in lab, and colonization experiments. In this paper, I focus on the latter; colonization experiments under full scale field conditions.

Lately, field experiments have become a common method for studying dispersal, colonization and resource utilization by saproxylic insects. Several small and large field experiments in boreal forest have created empty resource patches often arranging them in certain patterns related to management, distance from colonization sources etc. - and placed them out within the natural distribution area of relevant species (or sometimes outside, see Nilssen 1984). The type of new resource patches range widely in scale and type; from forest stands "treated" with certain retention levels or with forest fire (Eriksson et al. 2006, Hyvärinen et al. 2006), via artificially created high stumps and logs (e.g. Schroeder et al. 1999, Sverdrup-Thygeson \& Ims 2002, Gibb et al. 2006a, Johansson et al. 2006a, Johansson et al. 2007, Fossestøl \& Sverdrup-Thygeson 2009), artificial nest boxes that imitate cavities in old, hollow trees (Jansson et al. 2009), to sporocarps of fungi (Jonsell et al. 1999, Jonsson \& Nordlander 2006).

Sporocarps of fungi constitute clearly defined resource patches for the beetles, many of which are monophagous on specific fungi. Tinder fungus is commonly distributed over most of Fennoscandia and hosts several such beetle specialists. These characteristics make the system an attractive model system, and a handful of studies of tinder fungus and its inhabitants have been carried out the past 15 years, especially on the mono- phagous beetle Bolitophagus reticulatus (e.g. Nilsson 1997, Rukke \& Midtgaard 1998, Sverdrup-Thygeson \& Midtgaard 1998, Olberg \& Andersen 1999, Jonsell et al. 2003, Jonsson 2003).

A relevant question in field experiments is whether the assemblages colonizing the experimental resource patches are indeed representative of the true assemblages inhabiting the natural occurrences of these resources. This is important in order to judge the relevance of the results of such field experiments and to evaluate whether experimentally arranging empty resource patches is a sound method to use. This has been done for different types of resources previously: Jonsell et al. (2004) showed that the assemblage in artificially created high stumps mimic that of natural high stumps, and Jansson et al. (2009) state that among beetles found in hollow oaks which were either tree-hollow species, bird nest species, or wood rot species, $70 \%$ were also found in the artificial boxes. The beetle fauna in sporocarps has also been compared earlier, as Jonsell et al. (1999) found the fauna in experimental sporocarps of tinder fungus Fomes fomentarius (L. ex. Fr.) and Fomitopsis pinicola Fr. (Karst.) to be comparable to the communities in natural sporocarps from nearby areas. In the Jonsell et al. study, the experimental tinder fungus sporocarps were fresh and only placed out for a short time period ( 7 weeks). The sporocarps were mounted on wooden boards (meant to investigate between-tree colonization), or nailed to stems of dead birches bearing old sporocarps of tinder fungus (to study within-tree colonization). No between-tree colonization by $B$. reticulatus was observed in that study.

I wanted to study the beetle community in tinder fungus in an experimental set-up that resembled the natural situation as much as possible. Most of the associated beetle species utilize the sporocarps after they are dead, therefore I chose to use dead sporocarps and to mount them on recently dead birch stumps; their natural substrate in the study area. As dead tinder fungus sporocarps can remain intact for years (e.g. Nilsson 1997), and the flight period of $B$. reticulatus is short (Jonsell et al. 2003), I also felt it necessary to extend the time of exposure of the experimental sporocarps to three years.

In this study I focus on the use of experimental 
resource patches in the form of sporocarps of tinder fungus. With a close-to-natural experimental set-up, I investigate whether the colonizing beetle assemblages, including the much studied $B$. reticulatus, are representative of the assemblages in naturally occurring sporocarps in the same area. I also want to investigate what factors influence the colonization of empty experimental patches, especially to what degree the colonization of empty habitat patches relates to relevant dispersal sources in the surrounding forest. This was done by placing out empty sporocarps in a study area where the distribution pattern of the relevant fungivorous species was mapped in advance, at a scale of some hundreds of hectares.

\section{Methods}

The present study is based on two periods of field work. First, in 1992, all sporocarps of tinder fungus $F$. fomentarius within a 225 ha area of boreal, spruce dominated forest $60 \mathrm{~km}$ east of Oslo in south-eastern Norway were recorded and mapped (Fig. 1). The fungus grew on dead birch trees which could be found as single trees or in groups among the boreal coniferous tree species (see Sverdrup-Thygeson \& Midtgaard (1998) for more detailed description of study area). On each tree with $F$. fomentarius sporocarps, one third (but always at least one) of the dead sporocarps was collected and reared isolated for 2 months in a laboratory at $20^{\circ} \mathrm{C}$. Finally, all sporocarps were dissected to find beetle specimens remaining inside. This result represents the naturally occurring beetle community in tinder fungus in the area. Based on the assumption that presence of a beetle species in one sporocarp on a tree is a reasonable indication of presence also in the remaining, uncollected sporocarps on that tree (as shown for Bolitophagus reticulatus (Linnaeus, 1767) (Tenebrionidae) in Sverdrup-Thygeson \& Midtgaard (1998)), this presence denotes a potential dispersal source for the species (excluding of course the trees with only one sporocarp). This dataset is denoted "control dataset".

In April two years later, 80 dead but little decayed sporocarps of $F$. fomentarius were collected from a high density area west of Oslo. Care was taken to make the sample as homogeneous as possible, avoiding sporocarps diverging too much in size, decay or humidity. The sporocarps were placed in a super freezer at $-70{ }^{\circ} \mathrm{C}$ for several days in order to kill all beetle individuals inside. The sporocarps were then attached at $1 \mathrm{~m}$ height on $2 \mathrm{~m}$ high freshly cut birch trees (10-15 $\mathrm{cm}$ diameter). The birch tree poles were mounted vertically at random points in the study area, avoiding the border towards non-mapped areas (Fig. 1).

The experimental sporocarps were left in the forest for 3 summers and collected in the late fall of the third year. 3 sporocarps were destroyed over the course of the years, so the final number of replicates was 77. All sporocarps were dissected at once, and species were identified and recorded. In order to avoid possible confounding from pre-experiment beetle individuals killed in the freezing process and still not decomposed, only living beetles were used in further analyses.

I calculated colonization rate as the proportion of sporocarps that were inhabited by at least one beetle individual. I compared colonization rate between the experiment and the control both by comparing observed rates, and by a resampling procedure. In the resampling, I randomly selected 77 sporocarps from the pool of the 367 control sporocarps 10,000 times, and recorded the resulting resampled distribution of mean colonization rate. This was done to eliminate differences due to uneven number of sampling units of experimental and control sporocarps.

In addition, I wanted to compare the characteristics of the occupied experimental sporocarps, with a similar number of colonized control sporocarps. In order to achieve this, I ran a similar resampling procedure $(10,000$ iterations $)$ in which a subsample of 16 colonized sporocarps (i.e. the number of occupied sporocarps in the experiment) were selected randomly from the pool of 367 control sporocarps. I then recorded the distribution of the resampled cumulative species richness (for each set of 16 sporocarps), species richness per sporocarps, and number of individuals per sporocarp in the experimental sporocarps.

I also wanted to evaluate the effect of distance from known sources of dispersal for a species, if sufficient data for the monophagous species could be attained. As it turned out, this could only be done for one species (Cis jacquemartii Mellié, 


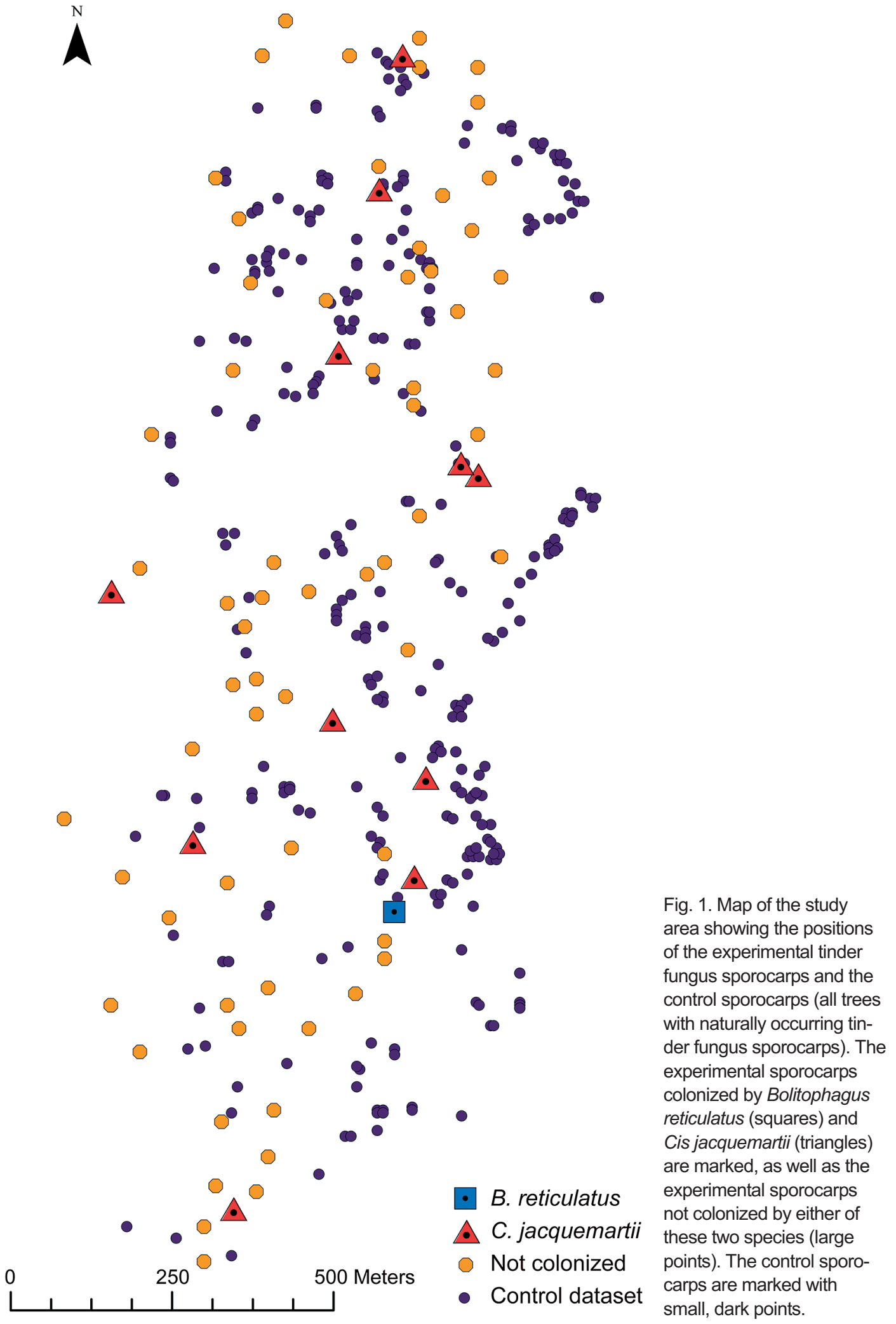


Table 1. Beetle species found in 367 sporocarps of Fomes fomentarius in the control study and in 77 sporocarps in the experiment, with abundance (no. of individuals), number of occurrences (no. of sporocarps it was found in) for each group.

\begin{tabular}{|c|c|c|c|c|}
\hline Species & $\begin{array}{l}\text { Abundance } \\
\text { in control }\end{array}$ & $\begin{array}{l}\text { Occurrences } \\
\text { in control }\end{array}$ & $\begin{array}{l}\text { Abundance } \\
\text { in experiment }\end{array}$ & $\begin{array}{l}\text { Occurrences } \\
\text { in experiment }\end{array}$ \\
\hline Cis jaquemartii & 2,466 & 181 & 167 & 11 \\
\hline Bolitophagus reticulatus & 1,121 & 96 & 5 & 1 \\
\hline Cis lineatocribratus & 159 & 26 & 1 & 1 \\
\hline Cis castaneus syn. C. nitidus, C. ater & 48 & 10 & 16 & 2 \\
\hline Dorcatoma dresdensis & 20 & 6 & - & - \\
\hline Leptusa pulchella & 16 & 14 & - & - \\
\hline Ropalodontus cornutum & 12 & 3 & - & - \\
\hline Rhizophagus dispar & 11 & 6 & - & - \\
\hline Ennearthron cornutum & 9 & 5 & - & - \\
\hline Triplax russica & 6 & 2 & - & - \\
\hline Leptusa fumida & 5 & 4 & 4 & 4 \\
\hline Cis bidentatus & 4 & 3 & - & - \\
\hline Cerylon fagi & 3 & 3 & - & - \\
\hline Lygisopterus sanguineus & 3 & 1 & - & - \\
\hline Acrulia inflata & 2 & 2 & - & - \\
\hline Dinaraea aequata & 2 & 2 & - & - \\
\hline Scaphisoma agaricinum & 2 & 2 & - & - \\
\hline Agonum fuliginosum & 1 & 1 & - & - \\
\hline Ampedus nigerinus & 1 & 1 & - & - \\
\hline Anaspis rufilabris & 1 & 1 & 2 & 2 \\
\hline Atheta myrmecobia & 1 & 1 & - & - \\
\hline Atrelus longiceps & 1 & 1 & - & - \\
\hline Biotoma crenata & 1 & 1 & - & - \\
\hline Chryptocephalus punctigel & 1 & 1 & - & _- \\
\hline Dinaraea linearis & 1 & 1 & - & - \\
\hline Gyrophaena boleti & 1 & 1 & - & - \\
\hline Gyrophaena sp. & 1 & 1 & - & - \\
\hline Lordithon Iunulatus & 1 & 1 & - & - \\
\hline Malthodes sp. & 1 & 1 & - & - \\
\hline Phratora vitellinae & 1 & 1 & - & - \\
\hline Quedius plagiatus & 1 & 1 & - & - \\
\hline Rhyncolus chloropus & 1 & 1 & - & - \\
\hline Notiophilus biguttatus & - & - & 1 & 1 \\
\hline Phloeocharis subtilissima & - & - & 1 & 1 \\
\hline Dorcatoma chrysomelinus & - & - & 1 & 1 \\
\hline Salpingus ruficollis & - & - & 1 & 1 \\
\hline
\end{tabular}

1848 (Ciiidae)), as the others had too few occurrences. I calculated the distance from each experimental sporocarp to the closest tree in the control dataset with presence of $C$. jacquemartii, excluding trees with only one sporocarp. The correlation between colonization and distance to nearest inhabited tree was then calculated by means of logistic regression.

Although the experimental sporocarps were carefully picked to maximize homogeneity, some variation in size was inevitable. Also, the field conditions at the randomly chosen locations dif- fered and the water content of the sporocarps upon collection varied accordingly. Therefore, volume (calculated as the volume of $1 / 4$ of an ellipsoid) and the water content (weight when collected at the end of experiment minus weight after dissection and drying at $40{ }^{\circ} \mathrm{C}$ for one week) of the sporocarps were measured. I then used logistic regression on the log-transformed variables to analyze whether difference in size or humidity influenced colonization. All statistical analyses were carried out in R (version 2.10.0) (R Development Core Team 2007). 

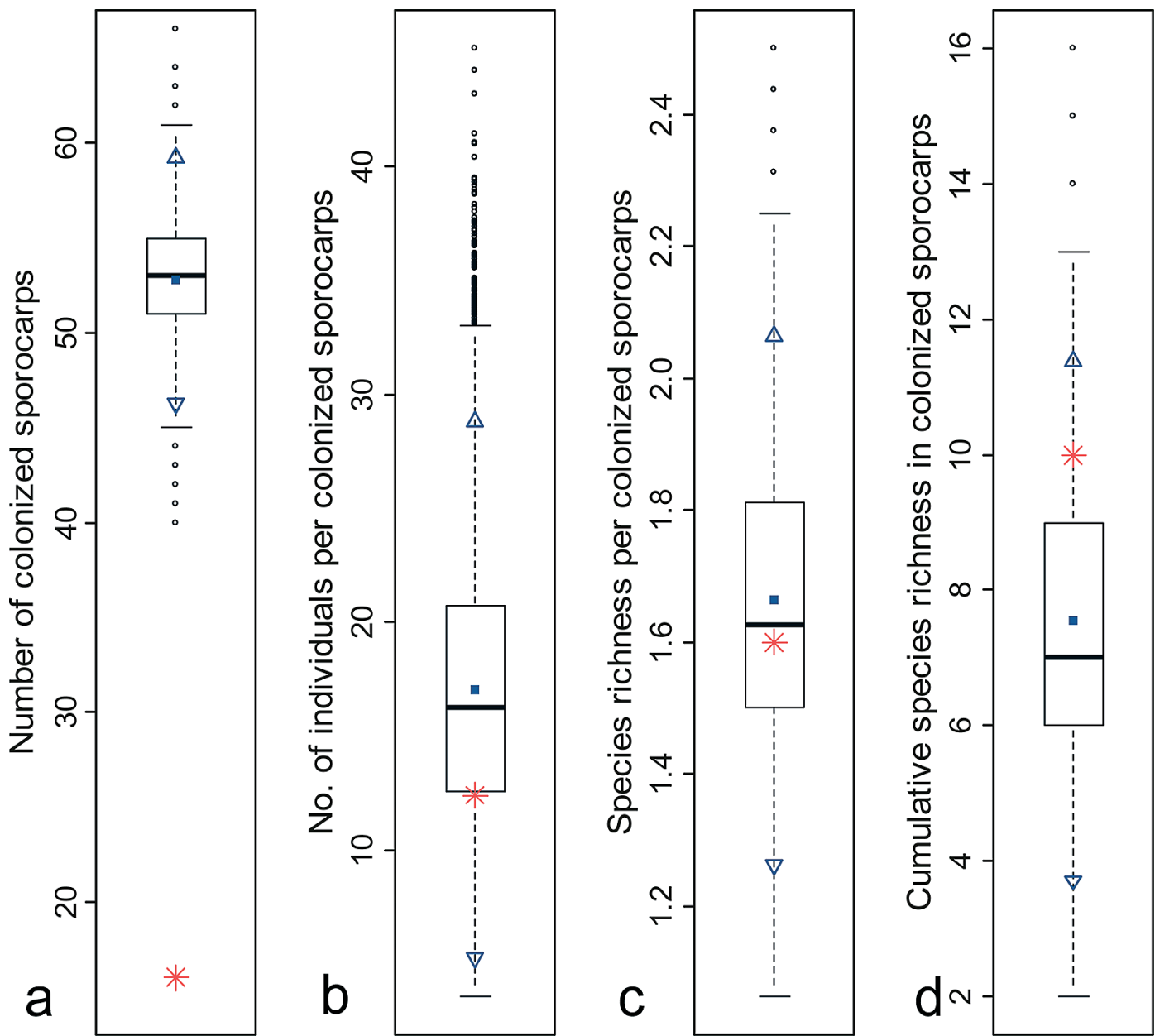

Fig. 2. Box plots of the results of resampling either 77 sporocarps from the control (the number of experimental sporocarps) (a) or 16 colonized sporocarps from the control (the number of colonized sporocarps in the experiment) (b-d). - a. No. of colonized sporocarps. - b. No. of individuals per colonized sporocarps. - c. Species richness per colonized sporocarp. $-d$. Cumulative species richness in colonized sporocarps. The star denotes the observed mean value from the experimental sporocarps. The 25 and 75 percentile and the median (indicated by the box and the line inside), mean (indicated as a square), confidence interval (arrowheads), minimum and maximum values ("whiskers") and outliers (dots) are shown.

\section{Results}

\subsection{Control dataset}

367 dead sporocarps were collected from 204 birch trees infected with tinder fungus inside the study area. $62 \%$ of the sporocarps contained one or more beetle individuals. In total, the sporocarps contained 3904 adult individuals representing 32 beetle species (Table 1).

$47 \%$ of the species were only present in one individual (singletons). C. jacquemartii was the most common species, with $63 \%$ of the individuals, while $B$. reticulatus was the second most common with $29 \%$ of the individuals.

\subsection{Experimental dataset}

The 77 sporocarps in the experimental setup were colonized by 199 individuals from 10 different beetle species, of which 5 species were singletons $(50 \%)$ (Table 1). Only 16 of the 77 sporocarps $(21 \%)$ were colonized by one or more species. In 
addition to the beetles, larvae of Raphidioptera sp. (Diptera), were found in 10 sporocarps and a Camponotus sp. (Hymenoptera) queen was found in one sporocarp.

\subsection{Comparison with assemblage in naturally occurring sporocarps}

The colonization rate of the experimental sporocarps was far lower than the proportion of inhabited sporocarps in the complete control dataset, and bootstrapping also confirmed that this low proportion was not a likely result when repeatedly resampling 77 sporocarps from the control dataset (Fig. 2a).

Still, when considering the sporocarps that actually were colonized, the resampling showed that they did not differ so much from the control dataset. The cumulative species richness, the species richness per sporocarps, and the number of individuals per sporocarp in the experimental sporocarps all were within the confidence intervals of the control sporocarps (Fig. 2b-d).

The relative contribution of each of the most abundant species was somewhat different in the experiment and the control dataset (Fig. 3). The three most common species occurring in the experimental sporocarps were among the 4 most common species in the naturally occurring sporocarps, but in the experimental sporocarps, one species dominated the assemblage with $84 \%$ of the individuals. In the control sporocarps, on the other hand, two species constituted almost $2 / 3$ and $1 / 3$ each.

The main difference was the low colonization of the experimental sporocarps by $B$. reticulatus. C. jacquemartii was the most abundant species in both datasets, with $84 \%$ of the individuals in the experiment and $63 \%$ in the control. The second most abundant species in the experiment, Cis castaneus Herbst, 1793 (syn. C. alter, C. nitidus) (Ciiidae), with $8 \%$ of the individuals, was ranked as the fourth most abundant species in the control with $1.2 \%$ of the individuals.

B. reticulatus ranged third in the experiment with $3 \%$ of the individuals, and second in the control with $29 \%$ of the individuals. Cis lineatocribratus Mellié, 1848 (Ciiidae), which was the third most common species in the control, was

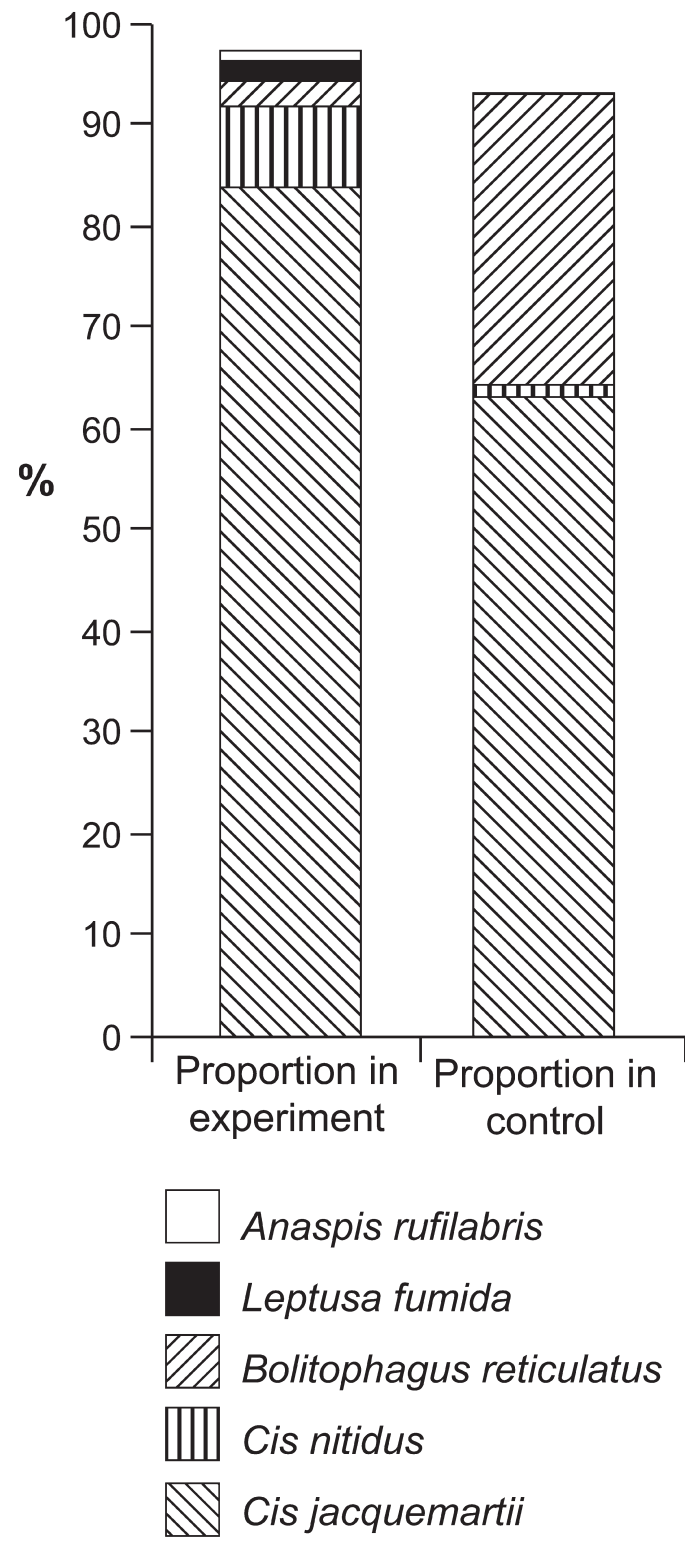

Fig. 3. The proportions of the five most abundant species in the experimental sporocarps, for both experimental sporocarps and the naturally occurring (control) sporocarps.

found in one individual in one of the experimental sporocarps.

\subsection{Single-species analysis of colonization}

\subsubsection{Cis jacquemartii}

Only one beetle species colonized a sufficient 
number of experimental sporocarps (more than 5) to justify single-species analyses, namely $C$. jacquemartii. This was the most abundant and the most commonly occurring species, having colonized $14 \%$ of the sporocarps during the three years of the experiment (Table 1 and Fig. 2).

When analyzing the presence/absence of $C$. jacquemartii as the response variable and distance to the nearest other inhabited tree as the predictor variable, there was no effect of distance to known dispersal sources (Logistic regression, $\chi^{2}=0.08, R^{2}=0.001, p=0.8$ ),

Even though the variance in volume of the experimental sporocarps was limited (ranging from $0.09 \mathrm{dm}^{3}$ to $0.4 \mathrm{dm}^{3}$ ), the sporocarps which were colonized were significantly larger than those that were not colonized (Logistic regression, $\chi^{2}=4.285, R^{2}=0.06, p=0.04$ ). I found no such effect of water content (Logistic regression, $\left.\chi^{2}=0.014, R^{2}=0.0002, p=0.91\right)$.

\subsubsection{Bolitophagus reticulatus}

$B$. reticulatus had colonized at least one sporocarp, where 5 living imagines were found when dissecting the sporocarps. This experimental sporocarp was $55 \mathrm{~m}$ away from the closest $B$. reticulatus-inhabited sporocarp. In addition, 12 sporocarps contained a total of 27 dead imagines, but as explained in Methods, dead specimens were excluded from analyses.

\section{Discussion}

\subsection{Low experimental colonization rate}

The proportion of experimental sporocarps that had been colonized three years after being placed out in the forest, is well below the proportion of inhabited natural sporocarps in the control $(21 \%$ vs. $68 \%$ ). Several factors can serve to explain this difference. For one, the colonization rate is probably underestimated, as only beetles alive at the endpoint of the field study was considered. This was done to avoid confounding colonizing individuals with individuals that had been in the fungus before the onset, and ensure a conservative rather than inflated judgement of colonization.

In addition, the pattern reflects that successful colonization of a suitable patch of a certain size is dependent not only on the distance from suitable sources and the sizes of these, but also on duration. The cumulative chance of a dispersal event reaching the patch will increase with time, although it might be counteracted by the slow deterioration of the patch. When reaching late stages of decay, the sporocarp will no longer be a suitable home for the associated species. This also relates to another factor possibly affecting the colonization rate - whether the relevant species were able to locate the experimental sporocarps in an efficient way. Several fungivorous insects rely on olfactory cues in finding suitable substrate (Jonsell \& Nordlander 1995, Jonsson et al. 1997, Johansson et al. 2006b), either in the form of pheromones or through attraction to specific compounds released from the host. Fäldt et al. (1999) did detect ethanol and acetic acid from newly dead $F$. fomentarius sporocarps, which may be important in attracting insects. Also Jonsell et al. (2003) found that traps baited with ethanol or a combination of ethanol and the fungus attracted $B$. reticulatus. Most species that have their larval development in F. fomentarius oviposit in dead or dying fruiting bodies (Fäldt et al. 1999), but even though I used birch tree poles for mounting to mimic the odors of decaying birch, olfactory cues connected to the dying stage of the sporocarp will be missed. This could have influenced the colonization rate.

The low colonization rates experienced in the study differ from those of a field experiment in and close to a birch forest in Sweden (Jonsell et al. 1999), where living sporocarps of $F$. fomentarius were removed from trees and placed out for only one summer. In that study, all sporocarps placed inside the birch forest with high natural abundance of $F$. fomentarius were colonized by at least one species, and ca $75 \%$ when placed out 150 meters away from the birch forest, in a monoculture of spruce. The proportion of natural $F$. fomentarius sporocarps that were inhabited by beetles is not given, but it was probably high.

In addition to differences related to decay stage of sporocarps, the difference between the studies can be due to the fact that the sporocarps of Jonsell et al. (1999) were placed out within and close by a significant source of dispersal for the relevant species, while the presence of such a 
'mainland' (sensu Harrison \& Taylor 1997) is missing in my study area. Instead, sporocarps inhabited by different species are spread out over the entire 225 ha area (see Fig. 1).

\subsection{Resemblance of natural species communities}

Although a low proportion of the experimental sporocarps in the study was colonized (Fig. 1), the assemblage in colonized sporocarps is still rather similar to the natural communities in the tinder fungus in the area, with respect to number of individuals and species per sporocarp. There is a trend of higher cumulative species richness in the experimental sporocarps, indicating that the $\beta$-diversity in the experimental sporocarps might be higher, but the difference is not significant. Such a pattern could make sense if placing out empty, dead sporocarps could be seen as a way to remove the effects of species succession and interspecific competition, by introducing empty resource patches in a decay stage where it would usually be filled up with established species.

The Cis-species that were common in the control, Cis jacquemartii, Cis lineatocribratus and Cis castaneus (syn. C. alter, C. nitidus) are all mainly developing in $F$. fomentarius in Fennoscandia, although $C$. castaneus can also occur in Piptoporus betulinus or Fomitopsis pinicola, and C. lineatocribratus can occur in F. pinicola (Thunes 1994, Jonsell et al. 2001, Jonsell \& Nordlander 2002). Both $P$. betulinus and $F$. pinicola were present, but in very low numbers in the study area.

C. jacquemartii was the most successful colonizer in the study, found in $14 \%$ of the experimental sporocarps (Table 1 and Fig. 2). The result of the distance analysis does not indicate any correlation between colonization and distance to sporocarps with an established population.

The species composition in F. fomentarius-infected trees had been mapped two years earlier, and could have changed somewhat in the meantime, and also the species composition in the remaining sporocarps could differ from those reared. Differences in the characteristics of the experimental sporocarps, such as the small differences in volume, also influence the result. Earlier studies have shown that $C$. jacquemartii is more abundant in larger sporocarps (Jonsell et al. 2001), which fits with the results on sporocarp size.

In addition to $C$. jacquemartii, $C$. castaneus was also found to have colonized a few experimental sporocarps (Table 1, Fig. 2). C. lineatocribratus was only found in one experimental sporocarp, even though it was common in the control sporocarps. Dorcatoma dresdensis Herbst, 1792 (Ptinidae), a monophagous species ranking as the fifth most abundant species in the control, was not found to have colonized any of the new sporocarps. The reason for this is not clear, but could be related to dispersal abilities, competition, or differences in factors triggering a dispersal event.

Jonsell et al. (1999) found that the beetles belonging to the genus Dorcatoma were more successful in colonizing distant patches than species of the genus $\mathrm{Cis}$, even though the latter are more widely distributed and more common in Fennoscandia. This does not fit with my results. As Ranius (2006) points out, the lack of data on the population size (the number of potential colonizers) could limit the generalizations of the Jonsell et al. (1999) results. Also, differences in the experimental setups could be a likely explanation.

The second most common species in the natural sporocarps, B. reticulatus, was found to have colonized at least one experimental sporocarp, in which 5 living beetles were found. Several earlier papers have focused on this monophagous tinder fungus beetle and the apparent mismatch between the fact that the species is rather common, and on the other side the fact that its incidence pattern has been shown to correlate negatively with isolation (Rukke \& Midtgaard 1998, Sverdrup-Thygeson \& Midtgaard 1998). Recent explanations to this distribution pattern and the absence of tree-levelcolonization in earlier colonization experiments (Jonsell et al. 1999, 2003) have focused on two facts: The species seems to have a short flight period (one week; Jonsell et al. 2003) and otherwise disperse mostly by walking (Nilsson 1997). It also displays attraction to the mixed odors of tinder fungus and ethanol (Jonsell et al. 2003). In the present study, these factors were taken into account: the prolonged exposure of the experimental sporocarps was intended to increase the 
chance of colonization by including three flight periods, and the use of freshly cut birch trees for mounting of experimental sporocarps was meant to give natural olfactory and visual cues to dispersing individuals. For the first time, colonization followed by successful reproduction by $B$. reticulatus between tree-level experimental patches was shown, although in low numbers. This indicates that the natural dispersal dynamics of the species operate on a rather long timeframe compared to many other beetles, and that long time studies over a larger area are necessary to detect colonization and reproduction in new habitat patches.

\subsection{Conclusion}

The study confirms that rich beetle assemblages can be found in the fruiting bodies of wood-decaying fungi, as shown by several authors (Jonsell \& Nordlander 2002, Komonen 2003). The study indicates that $C$. jacquemartii is a successful colonizer, well able to locate and colonize new substrate within the geographical scale covered in the study. The field experiment further documents between-tree colonization for $B$. reticulatus. The results indicate that experimentally arranging empty resource patches is a sound method to be used in studies of beetles in sporocarps, although there are certain differences in species composition compared to natural sporocarps that needs be studied further. Emphasis on mimicking natural conditions and including sufficient spatial and temporal scale can increase the chance of intercepting all associated species in natural rates in experimental set-ups.

Acknowledgements. I would like to thank my family for helpful field assistance and Sindre Ligaard for assistance in beetle identification. I am grateful to my colleagues at NINA, especially Odd Stabbetorp and Olav Skarpaas, for discussions, assistance with statistics and useful comments on earlier versions of this manuscript. The study received financial support from The Norwegian Research Council.

\section{References}

Balevièius, K. (ed.). 1992: Lietuvos raudonoji knyga [Red Data Book of Lithuania] — Lithuanian Department of Environmental Conservancy, Vilnius, Vilnius. 364 pp.

Buse, J., Schroder, B. \& Assmann, T. 2007: Modelling habitat and spatial distribution of an endangered longhorn beetle-A case study for saproxylic insect conservation. - Biological Conservation 137: 372-381.

Eriksson, M., Lilja, S. \& Roininen, H. 2006: Dead wood creation and restoration burning: Implications for bark beetles and beetle induced tree deaths. - Forest Ecology and Management 231: 205-213.

Finnish Environment Institute. 2000: Threatened species in Finland 2000. Insects: Beetles. - [www document]. URL http://www.ymparisto.fi/default.asp?no$\mathrm{de}=8570 \&$ lan $=$ en. (Site visited on 5 September, 2009).

Fossestøl, K. O. \& Sverdrup-Thygeson, A. 2009: Saproxylic beetles in high stumps and residual downed wood on clear-cuts and in forest edges. - Scandinavian Journal of Forest Research 24: 403-416.

Fäldt, J., Jonsell, M., Nordlander, G. \& Borg-Karlson, A. K. 1999: Volatiles of bracket fungi Fomitopsis pinico$l a$ and Fomes fomentarius and their functions as insect attractants. - Journal of Chemical Ecology 25: 567590.

Gibb, H., Hjälten, J., Ball, J. P., Atlegrim, O., Pettersson, R. B., Hilszczanski, J., Johansson, T. \& Danell, K. 2006a: Effects of landscape composition and substrate availability on saproxylic beetles in boreal forests: a study using experimental logs for monitoring assemblages. - Ecography 29: 191-204.

Gibb, H., Hjälten, J., Ball, J. P., Pettersson, R. B., Landin, J., Alvini, O. \& Danell, K. 2006b: Wing loading and habitat selection in forest beetles: Are red-listed species poorer dispersers or more habitat-specific than common congenerics? - Biological Conservation 132: $250-260$.

Grove, S. J. 2002: Saproxylic insect ecology and the sustainable management of forests. - Annual Review of Ecology and Systematics 33: 1-23.

Gärdenfors, U. (ed.). 2005: The 2005 red list of Swedish species - ArtDatabanken, Sveriges lantbruksuniversitet, Uppsala. 496 pp.

Hanski, I. 2000: Extinction debt and species credit in boreal forests: modelling the consequences of different approaches to biodiversity conservation. - Annales Zoologici Fennici 37: 271-280.

Harrison, S. \& Taylor, A. D. 1997: Empirical evidence for metapopulation dynamics. - In: Hanski, I. \& Gilpin, M. E. (eds.), Metapopulation biology. Ecology, genetics and evolution: 27-42 pp. Academic Press, San Diego. 512 pp.

Hyvärinen, E., Kouki, J. \& Martikainen, P. 2006: Fire and green-tree retention in conservation of red-listed and rare deadwood-dependent beetles in Finnish boreal forests. - Conservation Biology 20: 1711-1719. 
Jansson, N., Ranius, T., Larsson, A. \& Milberg, P. 2009: Boxes mimicking tree hollows can help conservation of saproxylic beetles. - Biodiversity and Conservation 18: 3891-3908.

Johansson, T., Gibb, H., Hilszczanski, J., Pettersson, R. B., Hjälten, J., Atlegrim, O., Ball, J. P. \& Danell, K. 2006a: Conservation-oriented manipulations of coarse woody debris affect its value as habitat for spruceinfesting bark and ambrosia beetles (Coleoptera : Scolytinae) in northern Sweden. - Canadian Journal of Forest Research-Revue Canadienne De Recherche Forestiere 36: 174-185.

Johansson, T., Olsson, J., Hjälten, J., Jonsson, B. G. \& Ericson, L. 2006b: Beetle attraction to sporocarps and wood infected with mycelia of decay fungi in oldgrowth spruce forests of northern Sweden. - Forest Ecology and Management 237: 335-341.

Johansson, T., Gibb, H., Hjälten, J., Pettersson, R. B., Hilszczanski, J., Alinvi, O., Ball, J. P. \& Danell, K. 2007: The effects of substrate manipulations and forest management on predators of saproxylic beetles. — Forest Ecology and Management 242: 518-529.

Jonsell, M. \& Nordlander, G. 1995: Field attraction of Coleoptera to odours of the wood-decaying polypores Fomitopsis pinicola and Fomes fomentarius. - Annales Zoologici Fennici 32: 391-402.

Jonsell, M., Nordlander, G. \& Jonsson, M. 1999: Colonization patterns of insects breeding in wood-decaying fungi. - Journal of Insect Conservation 3: 145-161.

Jonsell, M., Nordlander, G. \& Ehnström, B. 2001: Substrate associations of insects breeding in fruting bodies of wood-decaying fungi. - Ecological Bulletins 49: 173-194.

Jonsell, M. \& Nordlander, G. 2002: Insects in polypore fungi as indicator species: a comparison between forest sites differing in amounts and continuity of dead wood. - Forest Ecology and Management 157: 101118.

Jonsell, M., Schroeder, M. \& Larsson, T. 2003: The saproxylic beetle Bolitophagus reticulatus: its frequency in managed forests, attraction to volatiles and flight period. - Ecography 26: 421-428.

Jonsell, M., Nitterus, K. \& Stighall, K. 2004: Saproxylic beetles in natural and man-made deciduous high stumps retained for conservation. - Biological Conservation 118: 163-173.

Jonsson, M. 2003: Colonisation ability of the threatened tenebrionid beetle Oplocephala haemorrhoidalis and its common relative Bolitophagus reticulatus. - Ecological Entomology 28: 159-167.

Jonsson, M., Nordlander, G. \& Jonsell, M. 1997: Pheromones affecting flying beetles colonizing the polypores Fomes fomentarius and Fomitopsis pinicola. - Entomologica Fennica 8: 161-165.

Jonsson, M. \& Nordlander, G. 2006: Insect colonisation of fruiting bodies of the wood-decaying fungus Fomitopsis pinicola at different distances from an old-growth forest. - Biodiversity and Conservation 15: 295-309.

Komonen, A. 2003: Hotspots of insect diversity in boreal forests. - Conservation Biology 17: 976-981.
Kålås, J. A., Viken, Å. \& Bakken, T. (eds.). 2006: Norwegian Red List - Norwegian Biodiversity Information Centre (in Norwegian and English), Trondheim. 416 pp.

Lilleleht, V. (ed.). 1998: Red Data Book of Estonia — Eesti Teaduste Akadeemia. Looduskaite komisjon, Tartu. Available in English at http://www.zbi.ee/punane/english/index.html

Nilssen, A. 1984: Long-range aerial dispersal of bark beetles and bark weevils (Coleoptera, Scolytidae and Curculionidae) in northern Finland. - Annales Entomologici Fennici 50: 37-42.

Nilsson, T. 1997: Survival and habitat preferences of adult Bolitophagus reticulatus. - Ecological Entomology 22: 82-89.

Olberg, S. \& Andersen, J. 1999: Field attraction of beetles (Coleoptera) to the polypores Fomes fomentarius and Phellinus spp (Fungi : Aphyllophorales) in northern Norway. - Entomologia Generalis 24: 217-236.

R Development Core Team. 2007: R: A language and environment for statistical computing. R Foundation for Statistical Computing, Vienna, Austria. ISBN 3900051-07-0. — [www document] URL http://www.R-project.org.

Ranius, T. 2006: Measuring the dispersal of saproxylic insects: a key characteristic for their conservation. Population Ecology 48: 177-188.

Ranius, T. \& Hedin, J. 2001: The dispersal rate of a beetle, Osmoderma eremita, living in tree hollows. - Oecologia 126: 363-370.

Rukke, B. A. \& Midtgaard, F. 1998: The importance of scale and spatial variables for the fungivorous beetle Bolitophagus reticulatus (Coleoptera, Tenebrionidae) in a fragmented forest landscape. - Ecography 21: 561-572.

Schiegg, K. 2000: Effects of dead wood volume and connectivity on saproxylic insect species diversity. Ecoscience 7: 290-298.

Schroeder, L. M., Weslien, J., Lindelöw, A. \& Lindhe, A. 1999: Attacks by bark- and wood-boring Coleoptera on mechanically created high stumps of Norway spruce in the two years following cutting. - Forest Ecology and Management 123: 21-30.

Siitonen, J. 2001: Forest management, coarse woody debris and saproxylic organisms: Fennoscandian boreal forest as an example. - Ecological Bulletin 49: 1141.

Speight, M. C. D. 1989: Saproxylic invertebrates and their conservation. - Council of Europe Publication, Strasbourg. $81 \mathrm{pp}$.

Starzomski, B. M. \& Bondrup-Nielsen, S. 2002: Analysis of movement and the consequence for metapopulation structure of the forked fungus beetle, Bolitotherus cornutus Panzer (Tenebrionidae). — Ecoscience 9: 2027.

Sverdrup-Thygeson, A. \& Ims, R. A. 2002: The effect of forest clearcutting in Norway on the community of saproxylic beetles on aspen. - Biological Conservation 106: 347-357.

Sverdrup-Thygeson, A. \& Midtgaard, F. 1998: Fungus in- 
fected trees as islands in boreal forest: Spatial distribution of the fungivorous bettle Bolitophagus reticulatus (Coleoptera, Tenebrionidae). — Ecoscience 5: 486493.
Thunes, K. 1994: The coleopteran fauna of Piptoporus betulinus and Fomes fomentarius (Aphyllophorales: Polyporaceae) in Western Norway. - Entomologica Fennica 5: 157-168. 